\title{
Assessment of Water and Salt Balance in Manzala Irrigation and Dr. System Area
}

Maha fahmy, Walaa elNashar, Amgad khorshed

\begin{abstract}
The main objectives of the study aim at optimal exploitation of the water resources in Eastern Nile Delta region. Until now, the Ministry of Water Resources and Irrigation (MWRI) is managing water resources and the irrigation system by itself with high input of staff and high capital investment. The mission of MWRI is to ensure that Egypt's water resources are developed, allocated, used and preserved in a manner which is sustainable, equitable and efficient. The research work evaluated the water balance, the salt balance, the water quality and the management plans in the study area from August 2000 to July 2010, also, attempt a new water management plan. The water and salt balance first executed for the Eastern Nile Delta region. To create work breakdown structure, the Eastern Nile Delta region divided into two parts according to the irrigation and drainage systems. The first one is Manzala Irrigation and Drainage System (MIDS), the second is Ismailia Irrigation and Drainage System(IIDS). In this paper, a water and salt balance executed for MIDS. MIDS boundaries are Manzala Lake from the north, dammitta branch from the west, IIDS from the east and Greater cairo and IIDS from the south. Results of water balance showed gradually increasing of domestic and industrial water discharges from Greater Cairo to MIDS, the influent fresh water was almost constant and didn't completely follow ET demands and the intruding seawater was almost decreasing. Results of salt balance elements showed adding extra soil salt loads to MIDS area. The MIDS water and salt balance results didn't comply with MWRI mission.
\end{abstract}

